ARTICLES

\title{
The Relation between Academic Freedom and Free Speech*
}

\author{
Robert Mark Simpson
}

The standard view of academic freedom and free speech is that they play complementary roles in universities. Academic freedom protects academic discourse, while other public discourse in universities is protected by free speech. Here I challenge this view, broadly, on the grounds that free speech in universities sometimes undermines academic practices. One defense of the standard view, in the face of this worry, says that campus free speech actually furthers the university's academic aims. Another says that universities have a secondary democratic function, which cannot be fulfilled without free speech on campus. I identify shortcomings in both types of arguments.

\section{INTRODUCTION}

People sometimes talk as if "academic freedom" simply means something like "free speech as applied in academic settings." This understanding is often evident in popular discourse, and sometimes in scholarly writing too. However, most sophisticated scholarship on this topic nowadays recognizes that academic freedom is importantly distinct from free speechthat it is not aptly construed as just "part of the ordinary freedom that

\footnotetext{
* For valuable feedback and criticism, I thank two anonymous reviewers and several anonymous editors at Ethics, as well as Eric Barendt, Adam Dean, Toby Handfield, Jeff Howard, Kasim Khorasanee, Brian Leiter, George Letsas, Saladin Meckled-Garcia, Polly Mitchell, Crescente Molina, Scott Shapiro, and audiences at the UCL Law School, Queen Mary University, the Oxford Jurisprudence Discussion Group, the University of Tartu, and the University of Warwick. I'm also grateful to Amia Srinivasan; some of the ideas in this article evolved out of an earlier article we coauthored entitled "No Platforming."
}

(C) 2020 by The University of Chicago. All rights reserved. 0014-1704/2020/13003-0001\$10.00 
288 Ethics April 2020

is the birthright of citizens in a democracy." ${ }^{1}$ Most scholarly writing on academic freedom adopts a more nuanced-and at first blush, more plausible - view about the relation between academic freedom and free speech. I will call this more nuanced, plausible view the standard view. It is captured in remarks like the following, first from Erwin Chemerinsky and Howard Gillman: "We should think of campuses as having two different zones of free expression: a professional zone, which protects the expression of ideas but imposes an obligation of responsible discourse and responsible conduct in formal educational and scholarly settings; and a larger free speech zone . . . where the only restrictions are those of society at large. Members of the campus community may say things in the free speech zones that they would not be allowed to say in the core educational and research environment." "And in a similar vein, we have the following from Keith Whittington:

The ideal of academic freedom emphasizes that members of the faculty should have the independence to exercise their professional judgment and not be constrained by social, political, or financial pressures. . . . But the campus is home to more than the work of scholars. Universities have long offered an arena in which students and visitors engage with and advocate for ideas. Those debates are often boisterous and freewheeling. They reflect the chaos of American democracy rather than the decorum of the seminar room. What holds those two worlds together is a common commitment to taking ideas seriously, to exploring the unconventional ... and to holding accepted truths up for challenge and reconsideration. ${ }^{3}$

In sum, academic freedom and free speech are importantly distinct, but both kinds of freedom have important - and complementary-roles to play in the university's organization and governance. The university is a venue for overtly academic communicative activities, related to teaching and research, and these are to be protected by academic freedom. But it also plays host to other kinds of communicative activities, including commencement addresses, public lectures and debates, student society meetings, protest, political advocacy, and student journalism. These communicative activities should be supported, accommodated, and protected against content-based restrictions under the auspices of free speech.

1. David Bromwich, "Academic Freedom and Its Opponents," in Who's Afraid of Academic Freedom?, ed. Akeel Bilgrami and Jonathan R. Cole (New York: Columbia University Press, 2015), 27-39, 39.

2. Erwin Chemerinsky and Howard Gillman, Free Speech on Campus (New Haven, CT: Yale University Press, 2017), 77; emphasis in the original.

3. Keith E. Whittington, Speak Freely: Why Universities Must Defend Free Speech (Princeton, NJ: Princeton University Press, 2018), 7. 
Here I argue against this view of the relation between academic freedom and free speech. Specifically, I claim that the arguments that are or may be given on behalf of this standard view are unpersuasive. We have good reasons to uphold free speech as a basic civil liberty and good reasons to accept academic freedom as a governing principle in universities. But we do not have particularly good reasons, I will argue, for thinking of the university as a special venue for extra-academic speech, or for making that extra-academic speech immune to content-based restrictions, as if it were just another form of free-speech-protected public discourse. Academic discourse is meant to be free from ideological constraints - this is part of what academic freedom is there to ensure- but it may be, and indeed should be, subject to content-based restrictions, insofar as they are driven by a concern for intellectual quality and integrity. Content-based restrictions on speech, which are anathema to a free speech ethic, are thus an integral part of serious academic practice. And it is in keeping with a reasonable understanding of the university's proper social-political function, I will argue, for us to extend an academic communicative ethos across the whole campus. Universities can be run as discriminating, intellectually regimented discursive arenas. We are not obliged to turn universities into totally wide-open marketplaces of ideas.

Authors like Chemerinsky, Gillman, and Whittington believe that this is a seriously mistaken attitude, and their worries are shared not only by scholars but also by a broad public. Since the cultural transformations to the university sector brought about by student protest movements of the 1960s, most people who have anything to do with universities - academics, students, managers, and worried onlookers - have subscribed to some version of the standard view. My question here is whether this is the right view of things, not just as a matter of legal or institutional policy, in any given jurisdiction, but in virtue of some deeper, philosophical idea about what the university is supposed to be and do.

In Section II, I motivate this inquiry by expanding on the theses briefly sketched above. Following Robert Post, I argue that an aversion to content-based speech regulation, which is a central tenet of free speech, is at odds with the practices of content-based discrimination that are integral to academic practice. In light of this tension, as well as a further thesis about the relation between a university's institutional culture and the pursuit of its intellectual mission, I challenge the idea that universities have some kind of constitutive commitment to free speech.

In Sections III and IV, I examine two kinds of arguments that may be offered in response to this challenge. The first appeals to epistemic concerns. It says that the university's core epistemic purposes will be better served if the relatively disciplined communicative activities that occur in teaching and research settings are surrounded by a less regimented, more freewheeling communicative atmosphere on the wider campus. 
The second kind of argument appeals to democratic concerns. It says that universities, in addition to their epistemic mission, have a key role to play in affirming, modeling, and nurturing a democratic ethos. In order to carry out their role in supporting democracy, so the argument goes, universities need to embrace a campus free speech culture. I will criticize both kinds of arguments, and in doing so, I will defend an alternative way of thinking about the university and its communicative ideals. My proposal is compatible with a liberal politics, but it understands the university as an institution narrowly defined by its epistemic aims, rather than a theater for the enactment of civil liberties.

\section{TWO IDEAS OF A UNIVERSITY}

\section{A. Differences between Academic Freedom and Free Speech}

In order to see how the tensions between academic freedom and free speech can arise, we first need a working sense of what both sets of principles consist of. Let's begin with free speech. A free speech principle is "a principle under which speech is entitled to special protection from regulation or suppression." ${ }^{4}$ What does "special protection" mean, exactly? First, it means protection that extends beyond the normal immunities which, in a liberal society, are presumptively afforded to all conduct, verbal or otherwise. Policies adopted for the sake of some social goal "must provide a stronger justification when the attainment of that goal requires the restriction of speech than when no limitations on speech are employed." Second, "special protection," in this context, means that policies which suppress speech cannot be defended via an appeal to the claim that the ideas being suppressed are bad, wrong, offensive, or false. To uphold free speech is to have an "aversion to regulation on the basis of the content of the communication." "This aversion partly stems from "distrust of the ability of government to distinguish between the true and the false, the useful and the useless, the valuable and the worthless." ${ }^{\prime 7}$ But it runs deeper than that. A free speech principle, as widely understood, does not merely forbid censorship by the state. It enjoins the creation and maintenance of a free speech culture, in which all are encouraged to speak their minds and to work through their disagreements in debate and discussion, instead of trying to silence or ostracize opponents.

Principles of academic freedom superficially resemble free speech principles. They require special protection for (certain forms of) communicative conduct, and they oppose (certain forms of) content-based

4. Eric Barendt, Freedom of Speech, 2nd ed. (Oxford: Oxford University Press, 2005), 6.

5. Frederick Schauer, Free Speech: A Philosophical Inquiry (Cambridge: Cambridge University Press, 1982), 7-8.

6. Ibid., 101.

7. Ibid., 101. 
suppression of speech. But these caveats mark important differences. Academic freedom applies to a limited class of communicative activities, coming from a limited class of speakers. It is the name we give to the set of rights "through which professional academics may dictate, within reasonable limits, the terms of their work," including the right to "determine the fundamental content of research and publication" and to "make important decisions about the content and terms of teaching." ${ }^{8}$ One way of putting this is to say that academic freedom insulates academics in their professional conduct - insulates them against interference from government actors, overbearing administrators in their own institutions, and external pressure groups. ${ }^{9}$ In essence, academic freedom has a narrower scope of application compared to a generic free speech principle. But as a further consequence of this elementary difference in scope, academic freedom is also unlike a generic free speech principle in the characteristic means through which it is institutionalized. Academic freedom is characteristically institutionalized through specialized contractual arrangements - tenure being one notable example - which make it more difficult for academics, compared to other professionals, to be disciplined or dismissed if their employers disapprove of their methods in carrying out their work. ${ }^{10}$ Moreover, the profession-based nature of academic freedom also means that the freedom it gives the academic, in her work, is bounded by demands of professional competence. Academic freedom gives the scholar a right to teach and research as she sees fit, but it allows that these activities, unlike public discourse, are "essentially subject to quality controls on the basis of general professional standards of accuracy and coherence." 11 This qualifying limitation has no real analogue when it comes to the activities covered by free speech. ${ }^{12}$

8. Michele Moody-Adams, "What's So Special about Academic Freedom?," in Bilgrami and Cole, Who's Afraid of Academic Freedom?, 97-122, 101.

9. Ronald Dworkin is one author who, in his account of academic freedom, invokes this notion of 'insulation' for individual academics; see Ronald Dworkin, "We Need a New Interpretation of Academic Freedom," in The Future of Academic Freedom, ed. Louis Menand (Chicago: University of Chicago Press, 1996), 187-98, 187.

10. For an overview of the different kinds of contractual instruments used to protect academic freedom in universities in the United Kingdom, the United States, and Germany, see Eric Barendt, Academic Freedom and the Law: A Comparative Study (Oxford: Hart, 2010).

11. Ibid., 20. Or, as Brian Leiter says, academic freedom has definite limits, "but those limits are to be set by those with expert competence in the relevant Wissenschaft, not by offended members of the polity at large or by politicians or business leaders whose interests might be adversely affected"; see Brian Leiter, "Why Academic Freedom?," in The Value and Limits of Academic Speech: Philosophical, Political, and Legal Perspectives, ed. Donald Alexander Downs and Chris W. Surprenant (New York: Routledge, 2018), 31-46, 33.

12. The way I am defining academic freedom involves two simplifications. These are aimed at streamlining things, and my arguments do not hinge on them, but I should note them up front. First, academic freedom - understood in terms of the rights of the individual scholar - is often taken to protect the scholar's speech not only in professional teaching and research but also in extramural expression, e.g., commentary on political issues in 
Now, this is all compatible with the standard view, to a point. The standard view grants that academic freedom is not identical to free speech. What it says is that these two freedoms should coexist in universities, in a complementary fashion. But there is a further tension that makes this coexistence more fraught than it may initially seem. Under the prerogatives that the scholar is afforded by her academic freedom, the scholar needn't — and indeed, shouldn't — exhibit the deep-seated aversion to the content-based regulation of ideas that is enjoined by a free speech principle. Quite the contrary: academic freedom empowers academics to regulate other people's speech in a content-discriminatory way. ${ }^{13}$ Such regulation is in fact integral to the form of intellectual work that the academic performs. Robert Post offers a compelling analysis of this aspect of academic freedom. As he explains, academic work by its very nature involves appraising the quality of other people's ideas and arguments- how informed they are, how evidentially supported, coherent, or otherwise rationally defensible, relative to some set of intellectual standards that define the relevant discipline of inquiry - and then rewarding or amplifying the meritorious and reproving or withholding rewards from ideas and arguments that are ill-informed, incoherent, or otherwise intellectually subpar. In institutions where academic freedom reigns, academics are protected in performing this work and shielded against external interference in the judgments they make to this end. And in such environments, people's speech will routinely be suppressed because of substantive evaluations of its content by the domain-relevant authorities - evaluations which ignore any free speech-based aspiration to content neutrality. Post sums up this conflict in a discussion of how these broader theoretical issues play out in the realm of American constitutional jurisprudence: "The continuous discipline of peer judgment, which virtually defines expert knowledge, is quite incompatible with deep and fundamental First Amendment doctrines that impose a 'requirement of viewpoint neutrality' . . .

public forums. I will be setting extramural expression aside in what follows, apart from a brief comment in note 28. Second, as Dworkin observes, academic freedom in fact involves two different levels of insulation. In addition to protections for the individual academic, there is also the insulation of each institution from governments or corporations that might try, for example, to deter research that is contrary to their interests. At least one contemporary author favors a conception of academic freedom that places greater emphasis on the latter; see Frederick Schauer, "Is There a Right to Academic Freedom?," University of Colorado Law Review 77 (2006): 907-28.

13. Louis Menand explains one aspect of this: "Specialists within each specialized field have wide authority to determine who the new specialists will be, and in what the work of specialization properly consists. This authority insures a commensurately wide freedom of inquiry; but (and this is the important point) only for the specialist. For people who do not become members of the profession, this system constitutes not a freedom but an almost completely disabling restriction"; see Louis Menand, "The Limits of Academic Freedom," in Menand, Future of Academic Freedom, 3-20, 8. 
and that apply 'the most exacting scrutiny to regulations that suppress, disadvantage, or impose differential burdens upon speech because of its content' . . . the production of expert knowledge rests on quite different foundations. . . . Expert knowledge requires exactly what normal First Amendment doctrine prohibits." ${ }^{14}$ In response to Post's analysis, one may argue that free speech is just about government refraining from contentbased speech regulation. Person A's right to free speech is not infringed if a private organization decides not to use its resources to publicize A's views. This is indeed the case if we have a strictly legal notion of free speech: as a constitutional right held by individuals against the state, and nothing more. But this is a narrow way of construing what is at stake in this area. The demands of free speech are not exhausted by the duties associated with such a right. In the society that fully embraces free speech, the absence of content-based legal restrictions on speech is reinforced by the private citizen's aversion to groupthink and socially mandated orthodoxy. The ideal of giving every voice a hearing and the reluctance to suppress bad ideas - regardless of how badly informed or reasoned they are-are aspired to by the law and the individual alike. That, at any rate, is the classical liberal ideal of free speech, in its most famous Millian form. ${ }^{15}$ It is also what Post has in mind, and what those who object to "no platforming" and the like on free speech grounds must have in mind, at least in cases when

14. Robert C. Post, Democracy, Expertise, and Academic Freedom: A First Amendment Jurisprudence for the Modern State (New Haven, CT: Yale University Press, 2012), 9. For further elaboration of his account, see Robert Post, "Academic Freedom and the Constitution," in Bilgrami and Cole, Who's Afraid of Academic Freedom?, 123-52; Matthew W. Finkin and Robert C. Post, For the Common Good: Principles of American Academic Freedom (New Haven, CT: Yale University Press, 2009). On its face, Post's claim - that academic expertise involves imposing differential burdens on speech because of its content-may sound like an apologia for dogmatism. But academic disciplines are supposed to be antidogmatic, aren't they? Post is not denying this. His point is about how we judge whether ideas are intellectually credible within the defining parameters of an academic field. Post is not saying that experts may suppress ideas in academic discourses merely because they dislike those ideas. He is saying that the appraisal of ideas must follow disciplinary standards - as opposed to majority opinion, or the diktats of the politically powerful - and that formally credentialed disciplinary authorities are justified in applying those standards to promote credible ideas and demote shoddy ones. It is still the case, in principle, that any outlandish idea or hypothesis can receive a hearing in academic discourses. But again, there is a qualification: "scholars must be free to debate any academically controverted matter, so long as the debate ... proceeds on the basis of scholarly standards"; see Finkin and Post, For the Common Good, 38; emphasis mine.

15. The dangers of groupthink and ideological conformity that Mill identifies in $\mathrm{On}$ Liberty, and that he wants free speech to stand in guard against, are not dangers borne of the exercise of state authority in particular. The ethical thesis that we should refrain from suppressing disapproved ideas is meant to give rise to both a formal constraint on the power of government and a regulative ideal for informal social intercourse among private citizens. Indeed, at certain points Mill suggests that the latter is more important than the former, insofar as the form of ideological conformity that comes through informal social sanctions is more injurious to the realization of people's individuality than the form driven 
their objections pertain to private universities. ${ }^{16}$ With this more expansive understanding of free speech in the background, Post's point is that in order to advance the university's epistemic mission, academics should not, in their professional work, do what a free speech ethic enjoins - they should not exhibit an aversion to content-based speech restrictions.

So, proponents of the standard view must at least concede that the coexistence of academic freedom and free speech in the university necessitates a complex negotiation. The communicative climates in the university's "free speech zone" and its "professional zone" - to borrow Chemerinsky and Gillman's terms — are less alike than we might have initially supposed. When it comes to who speaks and what is said in the academic zone, academics are empowered to decide which ideas are heard. But

by state action. The greater danger to human liberty, Mill suggests, comes from a social tyranny "more formidable than many kinds of political oppression" since "it leaves fewer means of escape, penetrating much more deeply into the details of life, and enslaving the soul itself"; see John Stuart Mill, On Liberty (1859), in "On Liberty" and Other Essays, ed. J. Gray (Oxford: Oxford University Press, 1991), 1-128, 8-9.

16. In the United States the First Amendment imposes free speech obligations on state universities, whereas private universities are subject to such obligations only as a matter of voluntary self-regulation; see John Hasnas, "Freedom of Expression at the Private University," in Downs and Surprenant, Value and Limits of Academic Speech, 78-95. One might argue that this is the correct approach not just as a matter of American constitutional doctrine but as an abstract matter of right. State universities are state institutions, and thus any limitation on campus free speech, beyond what is strictly necessary in order for the university to fulfill its teaching and research functions, infringes the citizen's basic civil right to free speech. But this line of reasoning proves too much. Any public institution, in order to be effectively managed, needs to control how its communicative platforms and resources - at its operational premises, and under its insignia more generally - are utilized. The fact that a state university is a public institution does not give Joe Citizen a presumptive entitlement to speak, move, and associate however he pleases around its premises, any more than it gives him a right to speak, move, and associate however he likes on the premises of a publically funded arts institution or law enforcement agency. Now, one might reply that state university campuses are not simply premises for a public institution-that they have a grander purpose and status, qua arm of the state. I will consider some concrete arguments to this effect in Sec. IV. My point here is that the mere fact of a state university being a public institution is not enough to show that there must be a wide-scope right to free speech on campus. Indeed, even within the parameters of the First Amendment, as applied to American state universities, the individual's right to free speech on campus is still subordinate to the pursuit and realization of the university's intellectual mission. Martha Nussbaum explains this point as follows, quoting from Widmar v. Vincent, 454 U.S. 263, 268 n. 5 (1981): "The Supreme court has explicitly said . . . 'that students enjoy First Amendment rights of speech and association on the campus.' At the same time, the Court has recognized that the First Amendment 'must be analyzed in light of the special characteristics of the school environment.' A university is not like a public park: it is for education, and the Court has therefore 'never denied a university's authority to impose reasonable regulations compatible with that mission upon the use of its campus and facilities'"; see Martha Nussbaum, "Civil Disobedience and Free Speech in the Academy," in Academic Freedom, ed. Jennifer Lackey (Oxford: Oxford University Press, 2018), 170-85, 178. 
proponents of the standard view will insist that academics should not be given such control over who speaks and what is said in the free speech zone-for example, in commencement addresses, public debates, student society events, or the speech of student activists and journalists. Opinions that would likely be sidelined in the academic zone-opinions that are ill-informed, incoherent, or otherwise intellectually dubiousshould receive a hearing in these contexts, or, at any rate, they mustn't be denied a hearing as a result of being adjudged intellectually inferior. Once we are outside the academic zone, academic standards should not be used to restrict speech. As Chemerinsky and Gillman say, "campusespublic and private-must protect the freedom of the members of the academic community to use campus grounds for the broad expression of ideas, even if those ideas are expressed in ways that run contrary to the norms of professional conduct that apply within classrooms, scholarly gatherings, and department meetings." 17 And to be clear, the standard view does not just say that it would be welcome or agreeable if universities were to uphold free speech on campus. Rather, it regards the maintenance of a free speech zone as an institutional duty that derives from the university's essential mission. Whittington offers some particularly forthright commentary to this effect. He begins by asking, "If the production and dissemination of knowledge constitute the central mission of a modern university, then how is free speech related to that mission? Is free speech a pleasant (or unpleasant) add-on that we could easily remove without doing any real damage to the institutional integrity of the university itself?" His answer is, "I think not." "If we were to sacrifice free speech on college campuses, we would be subverting the core values and very purpose of a modern university . . . free speech is bred into the bones of a modern university, and any institution that sets those principles aside can no longer be meaningfully regarded as a proper institution of higher education." 18 These claims about what makes a bona fide university are not an idle theoretical conjecture. Part of the motivation for defending this vision of the university, by the authors I have been citing and others, is to justify opposition to universities limiting various forms of campus speech that have no direct connection to teaching and research. Consider, for instance, the campaign by the Foundation for Individual Rights in Education (FIRE) to highlight and criticize "disinvitation incidents" on US college campuses. Among the hundreds of incidents cataloged on FIRE's database, only a handful were occasions directly linked to teaching and research work organized by faculty. In the vast majority of cases, the speaking events were commencement addresses or campus speeches that ostensibly functioned as extracurricular entertainment, and the speakers being

17. Chemerinsky and Gillman, Free Speech on Campus, 76-77.

18. Whittington, Speak Freely, 28-29. 
challenged or silenced were not scholars but political figures, pundits, and entertainers. ${ }^{19}$ These kinds of disinvitations have no immediate impact on the ability of academics to teach and research, or on students to attend class, study, and take exams. And yet there has been, and continues to be, an enormous amount of soul-searching and hand-wringing about such incidents and what they portend for the future of higher education. The standard view is what intellectually underwrites this angst. If the maintenance of a free speech zone and free speech culture on campus is a vital part of what makes a university a proper university - as authors like Chemerinsky, Gillman, and Whittington suggest - then the cancellation of a talk by Ken Ham or a gig by Action Bronson may indeed be a cause for concern. ${ }^{20}$ But if that view is mistaken, then incidents like these seem like storms in teacups.

\section{B. Illustrating the Conflict: Ben Stein at the University of Vermont}

Why might one resist the standard view, then? Why hold that, contrary to the recommendations of this view, academic standards sometimes can be extended out and used to regulate speech outside of formal academic settings? Why might someone, who regards free speech as an important civil liberty, nevertheless push back against the idea that it is integral to the university's mission to sustain a free speech zone and a free speech culture on campus?

It is useful to bring an example to bear in reflecting on these questions. In 2009, the writer, actor, and lawyer Ben Stein had been invited to deliver a commencement address at the University of Vermont (UVM). After this invitation was publicized, there was a concerted letter-writing campaign - involving not only faculty at UVM but also high-profile academic figures elsewhere, including Richard Dawkins and P. Z. Myersaimed at persuading UVM's president, Daniel Fogel, to rescind Stein's invitation. The main concern motivating this outcry was that Stein had denigrated the integrity of the scientific academy and been an outspoken advocate of intelligent design creationism. ${ }^{21}$ Myers, one of the main agitators in this episode, expressed his sentiments about Stein's invitation in a post

19. For a full list of disinvitation incidents dating back to 1998 -with a total of 432 incidents cataloged, as of September 2019 — see FIRE's online database at www.thefire .org/how-to-use-the-disinvitation-database/.

20. Ken Ham is a young earth creationist and religious activist. Action Bronson is a rapper with a reputation for misogyny and homophobia. They were the targeted speakers in some of the disinvitation incidents cataloged on FIRE's database; see www.thefire.org /research/disinvitation-database/\#home/viewdisinvitationattemptdetails/572a43a840a2 d6462dba28e4/ and www.thefire.org/research/disinvitation-database/\#home/viewdis invitationattemptdetails/5a90181de122e927287a28d5/.

21. For an account of the case, see "Ben Stein Backs Out of Commencement Gig at Vermont over Views on Evolution," Chronicle of Higher Education, February 3, 2009, www .chronicle.com/article/Ben-Stein-Backs-Out-of/42353. 
addressed to UVM's students: "I don't know what the administrators at your school were thinking; this is a man with no qualifications other than a droning monotone and a stint on a game show. It's an expression of profound disrespect. ... And I'm really sorry for the biology department at UVM - it's a real slap in the face for the university to drag in this disgrace who has been a figurehead for a movement that is trying to replace science with superstition." ${ }^{22}$ On Fogel's account of the matter, Stein voluntarily withdrew from the talk after Fogel raised the concerns that had been conveyed to him in the wake of the invitation. ${ }^{23}$ In an interview with the university's student newspaper, Fogel explained his take on the issue as follows: "The fundamental concern of the people that wrote to me was that, while they are quite open to having a speaker with Mr. Stein's views on campus, they felt that he should not be honored at the commencement ceremony when so many of his views seemed to be affronts to the basic premises of the academy, about scientific and scholarly inquiry." 24 Stein's address would have fallen squarely in the university's free speech zone, rather than its professional zone, as Chemerinsky and Gillman mean those terms to apply. It would have been, to borrow Whittington's phrases, part of the chaos and freewheeling debate of public democratic argument, rather than the decorum of the seminar room. Nevertheless, at the urging of other academics in his own institution and beyond, Fogel treated this as a moment to be governed by something more like academic standardswhich allow ideas to be marginalized because of their dubious contentand not by free speech norms, on which dubious content is entitled to a full hearing and is to be answered with counterspeech instead of being muzzled. Of course, academic standards are not exacting simply for the sake of being exacting. The university's mission is to discover and disseminate knowledge of a kind that is only realizable via the regimented methods of inquiry that operate in mature academic disciplines. And part of how we fulfill this mission is by empowering academic experts to amplify or suppress viewpoints, based on a substantive appraisal of their merit relative to disciplinary standards. ${ }^{25}$ In the Stein incident, even though the

22. P. Z. Myers, "The University of Vermont Makes an Embarrassing Decision," Pharyngula, January 30, 2009, freethoughtblogs.com/pharyngula/2009/01/30/university-of -vermont-makes-an/.

23. Fogel's official statement can be viewed at http://straightfromthesource.files .wordpress.com/2009/02/campus-communication-commencement-speaker1.pdf.

24. See "UVM's President Responds to Questions about Commencement Speaker Ben Stein," Vermont Cynic, February 2, 2009, https://straightfromthesource.wordpress .com/2009/02/02/uvms-president-responds-to-questions-about-commencement-speaker -ben-stein/.

25. If we take promoting knowledge to be the point of academic freedom, does this commit us to a full-blooded enlightenment confidence about the academy's ability to discover objective, "capital-T" Truth? Not necessarily. John Dewey espoused a principle of academic freedom practically very similar to Post's, but without recanting his pragmatist doubts about the discoverability of capital-T Truth. How did Dewey square this circle? He 
occasion was only a commencement address, as opposed to a formal teaching or research event, UVM opted - to the disquiet of free speech advocates - to give priority to, and try to further the realization of, its epistemic mission, instead of setting up a platform for the airing of Stein's heterodox, outsider-ish opinions. ${ }^{26}$

Granted, the disinvitation of Stein probably did not advance the university's intellectual mission in any immediate, straightforward way. The research of UVM's biology professors and the learning outcomes for its students would not have tangibly suffered if Stein had spoken, one presumes. But it makes sense to adopt a broader perspective on the causal dynamics that are in play, in thinking about when and why communicative platforms in academic communities are either strictly moderated or opened up. Consider: would research in biological science at large be held back if, once a year, a random barstool pontificator got to air his opinions on evolution in Nature? Would the education of a university's biology students be hurt if, every now and then, the lectern was given over to a young earth creationist for a few minutes? Not according to the short-term, narrowscope counterfactual logic that these questions are implicitly premised upon. But we allow these communicative platforms to be strictly moderated, in a way that results in the near-total exclusion of epistemically dubious views, in part because we believe that the purposes of biological science are more effectively advanced, over the long-term, by our taking such an

did not believe that the unattainability of objective Truth made academic freedom pointless. On the contrary, he thought that it made academic freedom necessary. His view-paraphrased by Menand (see "Limits of Academic Freedom," 13) — was that "we don't need universities in order to preserve a static knowledge from the forces of change" but rather "to insure that knowledge will not remain static in the service of some vested interest." Richard Rorty takes another route to a similar destination. Academic freedom is there to aid the pursuit of knowledge, but whether we conceive of knowledge as (i) the apprehension of mind-independent reality or (ii) the widest possible intersubjective agreement on some topic is merely an ornamental gloss, which reflects the hopes and anxieties that we are gripped by in reflecting on our practices of inquiry; see Richard Rorty, "Does Academic Freedom Have PhilosophicalPresuppositions?," in Menand,Future of AcademicFreedom, 21-42. Whateverone makes of that characteristically arch suggestion, it indicates a way in which a skeptic about objective Truth can still sign onto a theory of academic freedom which is grounded in the aim of promoting knowledge.

26. For a discussion of how Post's account of academic freedom may be adapted to formulate a liberal argument for certain instances of "no platforming" in universities, see Robert Mark Simpson and Amia Srinivasan, "No Platforming," in Lackey, Academic Freedom, 186-209. Post himself proposes an application of his account to this end in Robert C. Post, "There is No First Amendment Right to Speak on a College Campus," Vox, December 31, 2017, www.vox.com/the-big-idea/2017/10/25/16526442/first-amendment-college -campuses-milo-spencer-protests. Broadly similar ideas are developed in Sarah Conly, "When Free Speech Is False Speech," in Downs and Surprenant, Value and Limits of Academic Speech, 299-310. 
approach. Research and education in this field work better if academically credentialed biologists have certain communicative spaces and platforms within which the epistemic standards that define their discipline are stringent regulative ideals. Among other things, this approach means that the experts' intellectual energies are not being constantly taxed by their having to answer the complaints of people who do not recognize their expertise, or value the knowledge that it generates. The setup embeds a form of rule consequentialism, if you like. Biologists suppress ignorant and specious ideas within various formal academic settings because they do better at achieving their epistemic aims by having contexts where they know they can postpone some of the tasks involved in the pursuit of those aims, for example, trying to defend the whole enterprise against fanatical opponents. The standards governing those spaces shouldn't, and at any rate couldn't, be applied to all public discourse on the relevant topics. But they can-and for the sake of our epistemic aims, it is not absurd to think they shouldbe broadly applied in the institutional home of the professionals responsible for achieving those epistemic aims, and who are the custodians of those standards.

To say all this - and to claim, in light of this, that it is perfectly in line with a proper understanding of the mission of a university to cancel a talk by someone like Ben Stein, based on an appraisal of his views as ignorant, badly reasoned guff - is not yet to disagree with Donald Downs and Chris Surprenant's statement, in the introduction to a recent collection of essays on academic freedom, that the healthy university is a kind of intellectual polis. ${ }^{27}$ The crucial question is, what sort of intellectual polis is the university supposed to be? The picture that I am recommending is one in which the communicative climate of the campus at large is characterized by similar kinds of rigor, thoughtfulness, and deference to academic expertise to those of the lecture theater or faculty research seminar. People are expected to comport themselves in a way that befits their being participants in a serious project of collective inquiry, and - as is already the case in formal teaching and research settings - this imposes standards on how they communicate with each other and, in various ways, on the actual substance of what they communicate. People like Stein who have repeatedly demonstrated a conspiratorial hostility to those standards, or who have otherwise revealed themselves to be unwilling to abide by them, are not handed valuable speaking platforms. The university is still a place for vigorous debate and disagreement. But the style and temper of disagreement are quite unlike debate in public discourse, not just in the sense of

27. Donald Alexander Downs and Chris W. Surprenant, introduction to Downs and Surprenant, Value and Limits of Academic Speech, 1-20, 2. 
being more mannerly but in the sense of being more earnest about the actual aims of inquiry, and hence rising above mere altercation. ${ }^{28}$

Notice that something like this rival vision of the university can also be invoked in defense of university "civility codes." Most of us-including proponents of the standard view-agree that lectures and seminars should not straightforwardly mirror "the chaos of public political discourse." The university's educative aims will be stymied if students are too intimidated, or too caught up in the melodrama of political skirmishing, to engage with the more demanding elements of their studies. Once all the controversial terminological packaging is bracketed off (e.g., in terms of claims about microaggressions or linguistic violence), the strongest case for university civility codes rests on a similar rationale, grounded in a commitment to the university's educational obligations. Students are on campus to learn. Some academics will expose students to distressing material as part of their learning. That kind of distress is an integral part of being a university student. But distress which results from being gratuitously attacked or insulted by one's peers is out of place on the campus common, for much the same reason that it is out of place in the seminar room itself. It is a kind of distress which is not integral to the targeted individual's learning experience, and which can greatly detract from it. ${ }^{29}$

28. One might question whether protection for extramural speech, as an element of academic freedom, would be warranted according to this picture. After all, it is sometimes academics who fail to behave like participants in a serious project of inquiry, e.g., by engaging in mobbing behavior, or engaging in puerile attacks on their rivals on social media. If the point of academic freedom is to help the university achieve its epistemic purposes, why extend protection to such unprofessional conduct? The question is a reasonable one, but I believe that under my proposed view of the relation between free speech and academic freedom, the rationale for protecting extramural speech looks much the same as under an orthodox theory of academic freedom. Protection for extramural speech has never been premised on the thesis that academics reliably carry over their more high-minded intellectual standards into commentary on political issues in public forums. Rather, for better or worse, it is premised on the idea that "the intervention of university authorities . . . in these circumstances creates an atmosphere of distrust between university administrators and academic staff, which makes it harder for the latter to teach and research freely"; Barendt, Academic Freedom and the Law, 274. (For his part, Barendt is unpersuaded by this argument; ibid., 275-77. For a defense of this sort of argument, see Finkin and Post, For the Common Good, 139-40.) In short, if there is a good case for protecting extramural speech, it rests on the contention that such protection conduces to a realization of the same epistemic aims for whose sake formal teaching and research practices are also protected.

29. Recent examples of analyses incorporating something like this rationale include Mary Kate McGowan, "On Political Correctness, Microaggressions, and Silencing in the Academy," in Lackey, Academic Freedom, 135-47; Christina Easton, "'Words that Wound' in the Classroom: Should They Be Silenced or Discussed?," in Downs and Surprenant, Value and Limits of Academic Speech, 167-86. Influential earlier discussions that are premised on this kind of rationale include Charles Lawrence III, "If He Hollers Let Him Go: Regulating Racist Speech on Campus," Duke Law Journal 1990 (1990): 431-83; Andrew Altman, "Liberalism 


\section{Three Argumentative False Starts}

There are two compelling lines of argument in defense of the standard view - and by extension, against this rival perspective that I am proposing - which I will examine in detail in Sections III and IV. But before turning to those, in the final part of this section I briefly remark on a few argumentative false starts that one may try out, in replying to the case sketched above.

First, one might claim that the university's broader culture does not affect teaching and research, and hence that the challenge I have presented for the standard view rests on a false premise. But this won't do. Advocates of the standard view generally want to say that institutional cultures are vital to the realization of the university's intellectual missionand that this speaks in the standard view's favor. For example, Robert Zimmer argues for the importance of free speech on campus, insofar as it helps to sustain a spirit of "open, rigorous, intense inquiry, in an environment of maximal intellectual freedom." ${ }^{30}$ In short, the case for or against the standard view does not hinge on whether the realization of the university's intellectual mission is affected by its institutional culture. Everyone, or nearly everyone, agrees that it is. The debate is over what kind of institutional culture best serves the university's mission.

Second, one might allow that the regulation of communicative activities in universities to further their epistemic aims is justifiable in principle, while arguing that the disinvitation of controversial speakers - and similar content-based interventions in campus discourse-is a disproportionate means to take in pursuing this end. But this begs the question. We do not see it as disproportionate when academics exclude views like Ben Stein's from research symposia and textbooks. In other public institutions whose aims include certain forms of inquiry, like public news media, we do not regard it as excessively censorious if producers decide not to allocate airtime to views which they judge to be specious or badly informed. The disinvitation of a speaker like Stein, in the UVM case, would only strike us as a disproportionate means if we had already concluded that the ideals that are native to the free speech zone should take precedence when a speaking platform is offered to someone who would normally be marginalized by the intellectual standards of the academy. But that is exactly the point at issue.

and Campus Hate Speech: A Philosophical Examination," Ethics 103 (1993): 302-17. Granted, each of these authors would resist the suggestion that the negative effects of being targeted with hostile speech on campus are merely distressing. While I am not discounting anyone's argument to that effect, the rationale for campus civility codes that I have outlined above will apply even where the negative effects in question are mere distress.

30. See Robert J. Zimmer, "What Is Academic Freedom For?," in Bilgrami and Cole, Who's Afraid of Academic Freedom?, 239-46, 245. 
Third, one might argue that there must be a free speech zone on campus because it is essential to the educational part of a university's mission. In its absence students become inhibited reasoners and stunted learners. The underlying concern here is important. If a university turns into an authoritarian fiefdom, with faculty persecuting students for believing "heretical" ideas, then its educational aims are dashed. But the view that I am putting forward-in short, on-campus discourse at large being governed by the norms of rigor and accountability to intellectual standards that apply in overtly academic settings - is one on which these things would equally be seen as a failure. As anyone who has been part of a healthy academic community can attest, the proper exercise of academic authority is not authoritarian. It brooks appropriately expressed dissent (and tries to answer it with evidence and arguments). It values heterodox opinion (if it is defensible relative to the intellectual standards that define the relevant field of study).

Now, it is true that some academics do have authoritarian tendencies. Some academics pressure their students into adopting predetermined views on issues where, according to the relevant disciplinary standards, there is room for reasonable, informed disagreement. This is lousy pedagogy at best, and professional malpractice in extreme cases. And it is not necessarily protected by academic freedom, since, as previously discussed, the academic's special freedoms and prerogatives are, in principle and in practice, subject to professional standards and quality controls. Negligently doctrinaire teaching should be liable to disciplinary pushback within the university's professional zone as things already stand, and the quasi-authoritarian behaviors that characterize such teaching would be equally liable to disciplinary action if the university's professional zone extended to govern communicative spaces across the whole campus. In sum, we do not need to invoke principles of free speech in order to explain why it is seriously wrong to suppress the independent thinking of students in a way that inhibits their learning.

Academics have good reasons for restricting ignorant, specious, or otherwise incompetent speech in formal academic communicative spaces, with a view to better realizing the epistemic purposes for whose sake academic communities of inquiry exist in the first place. That is relatively uncontroversial. But these reasons are also, prima facie, good reasons for the restriction of ignorant, specious, or otherwise incompetent speech in informal academic communicative settings, for example, commencement addresses or university-sponsored student society talks. Academic freedom clashes with free speech in academic settings, and if we understand 'academic settings' as encompassing the wider institutional environment in which teaching and research are conducted, then this poses a serious challenge to the standard view.

The most common argument for the standard view-and the natural way to address this challenge-appeals to epistemic goods: protecting 
free speech, and refraining from content-based regulation of communication on campus, furthers the same core epistemic ends as academic teaching and research. An alternative-but in principle complementary-argument appeals to democratic values. It says we should protect free speech on campus in order to further certain democratic ends. I discuss these two arguments in Sections III and IV, respectively.

\section{THE EPISTEMIC CASE FOR FREE SPEECH ON CAMPUS}

Disciplines of inquiry have one eye on the future. They seek to advance our achievements in the spheres of knowledge and understanding that they are organized around. They try to make it possible for people to know and understand more than is knowable and understandable now. They also have one eye on the past. They try to preserve a comprehensive record of the evidence, insights, and other factors that led people to see certain theories and conclusions as the most credible things to believe visà-vis the questions they speak to. And crucially, this preservation is meant to be something more than purely archiving. Advanced students in a mature academic discipline are not simply taught to recite an inanimate script which describes why theory $\alpha$ was superseded by theory $\beta$. They are tutored toward a vivid and vital understanding of theory $\beta$ 's intellectual merits over its predecessors and, more broadly, of how the questions to which it speaks relate to a range of other questions which jointly constitute a field of study.

It is not surprising, given all this, that Mill's arguments in On Liberty are routinely cited in discussions of academic freedom. Mill wants us to improve our current best understanding of the world. And where it is unclear whether our understanding in some area stands to be improved, he wants us to remain apprised of the reasons why the accepted views in that area are accepted and to apprehend all this in a way that ensures that we have living truth instead of "dead dogma." Mill believes that little else can serve these epistemic purposes as effectively as us hearing the accepted view on some issue being criticized by an informed and intellectually capable person who rejects it. His thesis is ostensibly a psychological one. You will not fully see what tells in favor of an idea until you have viewed it through the eyes of a credible interlocutor for whom it is not merely a hypothetical conjecture but part of their actual, living belief system. That empathic co-seeing might lead you to regard your current view of the matter in question as false, or incomplete, or simplistic. Or it might give you an enriched understanding of why your view is indeed the right thing to believe. ${ }^{31}$ If something like this picture is right, then it is crucial-for the 
fulfillment of their epistemic aims - that communities of inquiry are set up in a way that prevents the dogmatic silencing of heterodox ideas.

For advocates of the standard view, though, the question is how the setting up of free speech zones on a university campus helps to achieve this end. Chemerinsky and Gillman say that academic freedom is not enough to sustain an antidogmatic research culture; "that requires a second component as well: a willingness within the broader campus community to embrace and defend the unfettered exchange of ideas." ${ }^{32}$ But again, how is this aided by relaxing academic standards and embracing the undiscriminating, content-neutral ethos which is essential to free speech, when we shift from the seminar room to the wider campus?

Chemerinsky and Gillman's answer is that free speech is beneficial in "nurturing a spirit of tolerance within the broader campus community that allows all ideas to be subjected to debate and assessment." ${ }^{33}$ They claim that "the success of academic communities depends as much on continually reinvigorating this sentiment"-the sentiment that wrongheaded views are to be debated - as on having formal protections for academic freedom. ${ }^{34}$

There is something obviously right in this argument, but also something that is in need of further justification. The success of academic communities depends on them having a spirit of tolerance. As long as it is stated with a few careful caveats, that is true and important. The key caveat is that academic communities should not adopt an uncritical or mollifying stance toward work that manifests subject-relevant ignorance or methodological incompetence, relative to the appropriate disciplinary standards. However, when it comes to work that does meet these disciplinary standards, academic communities must evince a spirit of tolerance, allowing a platform for that work to be debated, whatever the substance of its conclusions.

That is the obviously right bit. What stands in need of further justification is the claim that the cultivation of this ethos in academic disciplines is aided by nesting the disciplines in an "anything-goes" free speech climate. Let's return to the Stein example to get a fuller sense of the doubts that one might have about this. Consider: how would allowing Stein to speak on campus help to foster a spirit of tolerance in the fields

32. Chemerinsky and Gillman, Free Speech on Campus, 69.

33. Ibid., 65 .

34. Ibid., 70. Notice that Chemerinsky and Gillman's argument on this front bears a resemblance to the argument for broader principles of free speech put forward in Lee C. Bollinger, The Tolerant Society: Freedom of Speech and Extremist Speech in America (New York: Oxford University Press, 1986). In both cases, a pivotal premise in the argument is that the community at large will somehow imbibe a tolerant spirit, as a result of it observing how authorities who have the power to restrict speech-including some speech that they have pro tanto good reasons to restrict-nevertheless conspicuously refrain from exercising that power. 
of inquiry that Stein's views pertain to, or in any other adjacent fields of study? At one level this is simply a request for specification. What is the mechanism supposed to be? Do we imagine that some academics with dogmatic tendencies hear Stein's address, or learn that he has been given a platform, and-having inferred that their institution is paying symbolic homage to an ethos of tolerance-resolve to be less dogmatic in how they engage with new ideas in their field? Or do we imagine, a bit more charitably, that this is a slow-burn transformation? Perhaps, at universities that regularly open speaking platforms to shills and trolls, academics-and their eventual successors, now starting out as students - gradually internalize the institution's "hear-them-out" attitude.

It is not absurd to postulate such mechanisms. But insofar as our method is speculative armchair sociology, we can just as easily posit rival hypotheses which would cast doubt on the standard view. At universities that offer speaking platforms to shills and trolls, academics may become disenchanted about the administration pandering to special-interest groups, or to the appetites of a student body more interested in debate as theatrical quarreling than debate as serious inquiry and analysis. They might jadedly come to believe that the management's attempts to cultivate a tolerant ethos are little more than a flimsy, post hoc pretext for hosting "edgy" events that make the institution more marketable to prospective students.

There is another reason to doubt that nesting academic disciplines in a campus-wide free speech zone aids in the cultivation of a tolerant ethos in academic study. Academic disciplines are run by people who are already acculturated into an ethos of tolerance, one which is grounded in the procedurally defined intellectual standards of the discipline they are trained in. The biology professors at UVM, where Stein was invited, hold their posts only by virtue of having internalized their discipline's principles and standards, relating to how evidence is cited and how the strength of one's conclusions is to be apportioned to the quality of the supporting evidence. They have an ongoing professional investment in the notion that hypotheses should only be assessed on the quality of reasons that can be enlisted in their support, and not on the basis of how they align with prevailing opinion. It is difficult to see the benefit in a university giving a platform to a figure like Stein as a symbolic gesture-one that is ambiguous at best - in order to nurture an ethos among its academics which is already present.

Even if we grant that this gesture may have a positive impact, it does not follow that the type of tolerance that the gesture aims to engender is appropriate vis-à-vis the university's epistemic purposes. It is helpful here to differentiate two different spirits of tolerance and, correspondingly, two views about how a spirit of tolerance may be fostered. One straightforward way to try to transition from dogmatism to tolerance, in a communicative arena, is to let every idea be heard. But part of what characterizes an academic community, as a special kind of communicative arena, is that 
it seeks to overcome the hazards of dogmatism in a different way-one that is harder to institute, but which has corresponding benefits. Academic communities aim to overcome dogmatism via methodological discipline. There are other things that characterize academic disciplines, including the valuing of technical virtuosity and innovation in the study of their subjects. But in addition to these typifying traits, part of what constitutes a field of study as an academic discipline is that it establishes methodological standards as regulative ideals for its work, while viewing these standards themselves as part of the discipline's proper sphere of inquiry. In essence, an academic discipline has standards for assessing the quality of claims and arguments, as well as a meta-methodological concern with the critical examination of those same standards. ${ }^{35}$ In a well-administered discipline, the methodological standards are implemented via institutional practices like anonymous review, external examination, and other anticorruption measures. These are all ways of trying to ensure that in the assessment of work - both in the evaluation of research by scholars and, where applicable, in the assessment of student learning - the discipline's methodological standards are the primary basis for assessments of quality and that the influence of other factors is cabined or minimized.

The point, to put it another way, is that academic disciplines have their own distinctive approach to cultivating and enacting a tolerant, antidogmatic intellectual ethos. Granted, this approach is not tolerant to the same degree as a laissez-faire bazaar, which welcomes the airing of ideas and arguments regardless of either their substantive conclusions or the methodological competence that they manifest. But still, this seems like a fitting way to implement an antidogmatic ethos in an institution whose raison d'être is the pursuit of knowledge and inquiry. The success of academic communities depends on them being willing to hear and consider any subject-relevant idea or viewpoint, but with the caveat that they should not adopt an uncritical stance toward work which demonstrates ignorance or incompetence relative to the local disciplinary standards. That is the distinctive mode of tolerance that universities need to be continually reinvigorating among their teachers and researchers. The gesture of opening up a platform to a speaker like Stein does not merely fail to reinvigorate the ethos in question; it positively subverts it-recall Myers's remark about this being a slap in the face.

One might object that my reasoning exhibits too much faith in the willingness and ability of academics to live up to the regulative ideals of

35. Stefan Collini argues that this meta-methodological concern is important not only for disciplinary research but also for giving a university education its distinctive character. One difference between university education and mere professional training, he says, is that the former "relativizes and constantly calls into question the information which training simply transmits"; see Stefan Collini, What Are Universities For? (London: Penguin, 2012), 56. 
their own disciplines. "Even in institutions dedicated to advancing truth and questioning past assumptions," as Chemerinsky and Gillman say, "the pressure to conform to dominant opinion is an ever-present threat." And being professionally invested in a set of high-minded methodological standards does not prevent academics from being biased or dogmatic in their appraisal of people's work. Academics are human beings, and they are prone to a range of human vices that compromise any ethos of tolerance that they might be professionally invested in. The point of having a free speech zone in universities, then, so one might argue, is to work against these vices, in cases where academic communities are becoming degraded and falling into closed-minded sectarianism.

Again, though, as reasonable as the desideratum is, it is not obvious how a free speech zone in universities is meant to secure it. Consider an example. Suppose you believe that neoclassical economics is a faulty framework for trying to understand how economies really work, one which is premised on a suite of tendentious assumptions, and whose preeminence in the economics departments of modern universities owes to its usefulness in legitimizing a global economic order that is favored by the wealthy. Given that view, and given the prevalence of neoclassical economics as a methodological framework, you might think that in (many) universities a wing of the academic community has abandoned serious disciplinarity and turned itself into a closed-minded, self-perpetuating sect. Now, in most of those universities there are large swathes of the student body - and many academics outside the economics departmentwho feel similarly. In most of those universities there are Marxist student organizations, which prosecute the case against neoclassical economics as a part of their activist work. The maintenance of a free speech zone on university campuses ensures that these dissident perspectives can be freely propounded. And none of it makes any appreciable dent in the position of neoclassical economics in the modern academy. The practitioners of neoclassical economics in the Faculty of Economics have heard the objections many times before and have such a huge argumentative advantage - in terms of knowledge and technical prowess - that their confidence in their framework's integrity is immune to being shaken by dissenters. Even students in the economics department, once they have progressed past their introductory coursework, may have a marked argumentative advantage (compared with the anticapitalist rabble-rousers in

36. Chemerinsky and Gillman, Free Speech on Campus, 70. Jason Brennan makes a similar point. Against the claim that universities are full of "disinterested, truth-seeking academics," he argues that academia is actually "full of ideologically motivated team players, status seekers, activists, and political hooligans"; see Jason Brennan, "Outside Funding to Centers: A Challenge to Institutional Mission?," in Downs and Surprenant, Value and Limits of Academic Speech, 96-114, 110-11. 
the Marxist Society) which makes them difficult to "convert." Indeed, visible dissent in the free speech zone may, in this case, be as likely to cement the controversial disciplinary creed as to dislodge it, since it exposes a sociological dynamic in which the credentialed experts all believe that neoclassical economics is sound, whereas most who oppose it are dilettantes.

This kind of worry generalizes. Academic disciplines are typically made up of people who share technical skills, esoteric vocabularies, and a large stock of common knowledge. As a result of this feature, an academic discipline which begins to conduct itself like a conformist sect is unlikely to change course simply as a result of its headquarters being located in a marketplace of ideas. Its course will be changed if a dissident cadre of students and, later, emerging scholars establish their disciplinary credentials, without losing sight of their reformist aspirations, and transform the discipline from within. Now, it may be that this is aided by the kind of campus culture the standard view recommends. Perhaps the agents of change for a degraded academic discipline need to test their mettle in a social climate that juxtaposes the rigors of disciplinary training to the wide-openness of a marketplace of ideas. But this is a slender reed on which to rest the case for the standard view. (The argument will look less fragile if we can flesh it out with reference to examples of individuals or groups who drove epistemically propitious reforms in their disciplines, and whose willingness and ability to play this role can be traced in some way to the formative impetus of a campus free speech culture.)

Here is one more angle to consider with the epistemic argument for the standard view. Set aside the whole issue of tolerance and dogmatism. Think of an academic community that is working as it should: plying its trade in accord with its methodological standards, welcoming a diverse range of viewpoints that are defensible by the lights of those standards, not letting its inquiry devolve into excessively politicized quarrels, andas a result of all this good practice - contributing to the advance of knowledge in its field. A community like this does not need to be nested inside a larger campus community with a wide-open marketplace of ideas. It could function as an autonomous institute, in an office block somewhere, and carry on working much the same. But perhaps this academic community will do an even better job if it is headquartered in an anything-goes campus with a robust free speech zone. Probably all academic disciplines have some sources of impetus which nudge their practitioners toward novelty and "blue-skies" experimentation, and which are internal to their own practices. But maybe a scholar is given more and better kinds of impetus of this kind by working in a special institutional setting-one where, while walking from her office to the lecture theater, she crosses paths with anarchists, art punks, religious zealots, future billionaires, and loopy eccentrics? Dewey spoke of universities as experiment stations, and Whittington - echoing this sentiment — claims that universities have 
a responsibility to provide "a forum for the new, the provocative, the disturbing, and the unorthodox." ${ }^{37}$ Maybe being in such an environment is part of what emboldens academics not only to tolerate outré ideas but also to champion them.

This seems like a more promising way to develop an epistemic argument for the standard view. Why? Because it is premised on a non-absurd hypothesis about the contribution that the free speech zone can make toward academic disciplines and their constitutive epistemic aims. Crucially, on this view, the contributions of the free speech zone are neither

- unwelcome, because they are in tension with the disciplinary intellectual standards; nor

- redundant, because they encourage an ethos already embedded in those standards; nor

- futile, because they are bound to be viewed as amateurish relative to those standards.

It is a hypothesis. Before it can be turned into a good argument, a few complicating factors must be considered. First, it may be that some disciplines benefit from being immersed in a free speech zone while others are undermined. Second, much of the creative impetus that comes with being located in a campus might just owe to academics encountering practitioners in other fields and their alternative ways of doing things. If so, then what we are considering is an argument not so much for the standard view as for opening up spaces for better cross-disciplinary interaction. Third, as Kevin Zollman's research shows, we can start with a few plausible assumptions about the motivations and practices of researchers and from them derive a number of surprising conclusions about what kind of communal structures of inquiry best conduce to the realization of our collective epistemic aims. Communities of inquiry work in weird ways. $^{38}$ Our intuitive guesses about what kinds of institutional and

37. Whittington, Speak Freely, 55. The quote from Dewey comes in the same part of Whittington's book and is drawn from American Association of University Professors, "Report of the Committee of the American Association University Professors on Academic Freedom and Academic Tenure," School and Society 3 (1916): 109.

38. For example, suppose that a research community is interested in a promising hypothesis, $\mathrm{H}_{2}$, which conflicts with an accepted theory, $\mathrm{H}_{1}$. Suppose that as-yet-undiscovered evidence would reveal $\mathrm{H}_{2}$ 's theoretical superiority to $\mathrm{H}_{1}$. But suppose that certain data are gathered, by some in the community, which misleadingly suggest that $\mathrm{H}_{2}$ is false. If all researchers in the community have knowledge of everyone else's data, then the whole community will be deterred, under these conditions, from researching a superior hypothesis. But if the community is in a more "siloed" state, then the misleading evidential deterrents for investigating $\mathrm{H}_{2}$ won't affect all researchers, and hence the community is more likely to learn of $\mathrm{H}_{2}$ 's merits. With this sort of case in mind, Zollman defends the counterintuitive thesis that a research community can be more successful in making discoveries if it is in a communicatively siloed state, where subgroups operate with little knowledge of the results 
communicative structures are likely to yield the epistemic results that we are hoping to achieve are to be taken with a grain of salt - or better yet, refined, tested, reformulated, and so on.

The idea that being surrounded by an "experimental vibe" makes academics more intellectually daring is a reasonable starting hypothesis, and one which, if it could be evidentially supported, could be built up into a good argument for the standard view. But as things stand, the epistemic arguments put forward on behalf of the standard view are at best incomplete. It is a complex question which conditions conduce to the realization of the university's epistemic aims. It may be that the establishment of campus free speech zones is a step in the right direction. But this is not some a priori truth. To defend the standard view, we first need to work with some more precise hypotheses, about exactly what role a free speech zone might play in the realization of the university's epistemic ends, and we should take care not to assign a function to the free speech zone which is in tension with those ends, or else just redundant.

\section{THE DEMOCRATIC CASE FOR FREE SPEECH ON CAMPUS}

Alternatively, a proponent of the standard view might argue that we need to maintain a free speech zone in universities regardless of whether this furthers the university's epistemic mission. The university's purpose is not only to discover and disseminate knowledge; universities also play a role in modeling, instilling, and commending a certain kind of democratic ethos. And they cannot fulfill this part of their mission, one might argue, unless they play host to a wide-open free speech culture. This argument would lose whatever prima facie plausibility it has if it said that the university's democratizing mission was more important than its epistemic mission. But it needn't go that far. All it needs to say is that "universities are critical molders of democratic citizens" and that this is "a by-product of universities performing their primary mission of educating students." 39 Zimmer develops this line of argument as follows: "The issues society faces are complex without simple answers. And in general, it

of other subgroups; see Kevin J. S. Zollman, "The Communication Structure of Epistemic Communities,” Philosophy of Science 74 (2007): 574-87. Zollman's approach, in developing this argument, involves a combination of statistical and game-theoretic modeling, to predict the types of research behaviors and outcomes that are likely to follow the establishment of different kinds of communicative structures in research communities. He uses similar methods to argue for other similarly counterintuitive theses, e.g., that a "hands-off" regulatory approach is less effective, in realizing the aims of inquiry, than one which actively encourages the investigation of unpopular hypotheses; see Erich Kummerfeld and Kevin J. S. Zollman, "Conservativism and the Scientific State of Nature," British Journal for the Philosophy of Science 67 (2015): 1057-76.

39. Whittington, Speak Freely, 18. 
is universities' openness to ideas, to analytic debate, to rigor, and to questioning, and the provision of an umbrella, and in fact safe haven, for clashing thought and perspectives, that best illuminate societal, scientific, and humanistic issues. In a world that tries to oversimplify, universities should demand analysis of inherent complexity ... in a world that creates an 'us-versus-them' approach to argument, we should support comfort with divergent views." ${ }^{40}$ Notice how, on Zimmer's account, the job of the university, in helping society deal with complex issues, is not just to supply the more complex answers when simple answers won't do. Its job, rather, is to inculcate a more enlightened mind-set in the way that we-society at large - face up to those issues, one that does not retreat into reductive tribalism or shy away from the complexity, but which instead faces the complexity with a spirit of sobriety, patience, and respect for one's argumentative opponents. And the way that academics help with this is not just by interjecting in debates to say, "Wait, the issues are more complex!" It is by embodying a vocational role that models and honors serious debate - debate that goes beyond mere altercation - in a way that can then be held up as an aspirational ideal for all of society.

One would have to hold a very single-minded view of the university's purposes to oppose all this. However great the effect might be, it seems hard to deny that a thriving university sector could play this role in a democratic society and that this could be beneficial.

But as with the epistemic argument, the crucial question, vis-à-vis the implications for the standard view, is why we should think that universities would do better at this if they embraced a campus-wide free speech ethos, instead of an ethos in which the communicative atmosphere of the campus at large is characterized by the same kinds of academic standards that govern teaching and research. Both Whittington and Zimmer see the university's democratizing mission as a part of why free speech is essential to university life. But the norms and culture of academic freedom seem to model the democratic ethos in question better than the norms and culture of free speech. This is brought out in Michael Lynch's account of the justificatory basis of academic freedom - an account which especially stresses the academy's role in democratic formation. Teaching and research in universities cause debates about social issues to be better informed, they model the justificatory practices of rational inquiry, they instill critical thinking skills, and, in all these ways, they fortify people's capacity to engage in dissent against authorities. These capabilities are vital to the health of a democratic order, and academic freedom protects the teaching and research practices that nourish them. ${ }^{41}$

40. Zimmer, "What Is Academic Freedom For?," 241.

41. Michael P. Lynch, "Academic Freedom and the Politics of Truth," in Lackey, Academic Freedom, 23-35. 
If we believe that it is part of the university's mission to produce good democratic citizens, then universities should be pushing students to outgrow a simplistic idea of public debate, on which every opinion is just as entitled to a proper hearing as any other. Universities should be fostering not only a culture of respect for dissenting opinions but also a sense that the value of dissent hinges on its being intelligent, coherent, and evidentially supported. Granted, it may be a condition of democratic legitimacy that the dissent of an ignorant contrarian is accommodated on the same terms as the dissent of an informed citizen. ${ }^{42}$ But a democracy full of ignorant contrarians is in trouble. It is unclear, then, why a university which is governed by the ideologically open but intellectually stringent norms of academic discourse will do better, in attaining to its democratizing purposes, by loosening the standards that govern communication, once we step outside overtly academic settings and onto the wider campus.

One prima facie viable answer to this question is that a university might conceive of the broader campus as a kind of training ground for the hurly-burly of a wide-open democratic culture. The university might think that a good way — or indeed, the best way - to facilitate this training is to allow the campus to be a forum in which students experience the tumultuousness of totally unfettered debate. ${ }^{43}$ Indeed, this "democratic training wheels" logic could even extend back into the classroom. Maybe the core epistemic mission of the classroom can be balanced against a secondary democratic-formation mission, in a way that sometimes justifies the professor in allowing a totally wide-open debate - unconstrained by considerations of disciplinary standards - even where this temporarily compromises or undermines the inculcation of knowledge for students in that setting. Seana Shiffrin suggests something along these lines. She says that a classroom which has a "full-blown commitment" to free speech "plays a role in exemplifying, reinforcing, and training citizens in democratic

42. This idea - that there is a tight connection between democratic legitimacy and the robust protection of free speech rights in the public sphere-is part of the broader theoretical background for Post's account of academic freedom in Democracy, Expertise, and Academic Freedom. For an innovative elaboration of this type of theory of democratic legitimacy, see Eric Heinze, Hate Speech and Democratic Citizenship (Oxford: Oxford University Press, 2016).

43. Post expresses some openness to this kind of argument: "Our universities might support student-invited speakers because they wish to create a diverse and heterogeneous campus climate in which students can learn the democratic skills necessary to negotiate a public sphere filled with alien and cacophonous voices. Universities may wish to educate students in practices of citizenship by encouraging a wide variety of student groups to invite outside speakers to recreate within the campus a marketplace of ideas"; see Robert C. Post, "The Classic First Amendment Tradition under Stress: Freedom of Speech and the University," in The Free Speech Century, ed. Geoffrey R. Stone and Lee C. Bollinger (New York: Oxford University Press, 2019), 106-22, 119. 
values of toleration and openness to criticism," in a way that a "dictatorial classroom"-roughly, one where the professor expects discussion to attain to formal disciplinary competencies - does not. "The former instils disciplinary expertise within an environment that remains as open as possible to input from all comers and to criticism. It thereby operates as a forum and exemplar of democratic legitimating activity, whereas the dictatorial classroom, however powerful it is at instilling . . disciplinary competence . . . is in tension with democratic values." ${ }^{45}$ We can quibble with Shiffrin's use of the word 'dictatorial' to describe a classroom that resists a full-blown commitment to free speech and exhibits the bounded form of tolerance which is characteristic of academic disciplines. (Recall, from Sec. II. $C$, the difference between academic authority and authoritarianism.) But even if the phrasing is softened in a way that is more flattering to my proposal, the general point remains. Universities can be thought of as institutions which, in addition to upholding their epistemic mission, ought to be training good democratic citizens and facilitating democratic legitimating discourse. If we extend the ideologically open but intellectually stringent norms of academic discourse, to cover all speech that takes place in the university's orbit, this could make the secondary goals harder to achieve. Having a free speech culture on the campus at large, and sometimes in the classroom as well, could help.

But even if we find something appealing in this, it is not enough to vindicate the standard view's insistence that universities must prioritize free speech, or that free speech is somehow a defining ideal for universities. For one thing, notice that even a university which does not give any special priority to free speech, and which instead opts to extend the more stringent communicative norms of academic discourse across the whole institution, can still be properly understood as working in the service of an important democratic value. As Post's account of academic freedom emphasizes, the university's core epistemic goals, in research and education, are of vital importance in establishing and enriching a society's democratic competence, that is, its collective capacity to render intellectually adequate and empirically well-informed judgments about the matters of public concern which government must address. ${ }^{46}$ For a university to prioritize the furthering of democratic competence - as we might now view the Stein episode, from Section II - is not to deny the importance of democratic legitimation. It is merely to delegate the facilitation of democratic legitimating discourse to other social institutions.

44. Seana Valentine Shiffrin, "Sincerity and Institutional Values," in Speech Matters: On Lying, Morality, and the Law (Princeton, NJ: Princeton University Press, 2014), 182-223, 213.

45. Ibid., 213.

46. Post, Democracy, Expertise, and Academic Freedom, 27-43. 
In order to have a compelling democratic argument for the standard view, we are going to have to claim that such delegation is a dereliction of the university's duties. To make such a claim is to demand not only that the university take the lead in advancing our collective epistemic aims, and that it play a role in the formation of a healthy democratic citizenry by furthering our democratic competence, but also that it do all these things while assisting in the legitimation of our democratic institutions. It is to think of the university as democracy's Swiss army knife. There may be good reason for a particular institution to aspire to all this if it believes that the difficult balancing acts can be carried off. But it seems rather less plausible to claim that it is a dereliction of duty to temper this aspiration and to instead cultivate a campus-wide discursive culture that puts intellectual values first - especially given that those values are themselves locatable in a network of democratic ideals. For the advocate of a democratic argument for the standard view, the key argumentative burden that remains is to explain why universities must be conceived of in a way that leads to the more onerous assignment of duties. Why should we think of universities as being obliged to join with other institutions in facilitating the discursive activities that legitimate democratic government? Why couldn't their contribution to a democratic politics just consist in the improvement of the citizenry's democratic competence? ${ }^{47}$ If it were possible for the university to further all of these democratic desiderata simultaneously, with no real downsides, then that would be the issue settled. But I have tried to give an indication of what some of the downsides are, or might be.

Advocates of the standard view might claim that the argumentative burden is actually the other way around: why shouldn't we think of universities as obliged to facilitate democratic legitimating discourse? This

47. We get the beginnings of such an argument in Dworkin's defense of academic freedom. His proposal resembles a "democratic formation" account, but it puts greater emphasis on the liberal ideal of ethical individualism, rather than the democratic ideal of selfgovernance. Academic freedom is warranted because it "represents and reinforces the ideal of ethical individualism . . . by creating a theater in which personal conviction about the truth and value is all that matters"; see Dworkin, "We Need a New Interpretation," 190. Note that the "ethical individualism" invoked here closely resembles the ideal of "moral independence" that Dworkin appeals to in explaining the grounds of free speech; see, e.g., Ronald Dworkin, "Is There a Right to Pornography?," Oxford Journal of Legal Studies 1 (1981): 177212. For Dworkin, then, these twin freedoms-academic freedom and free speech-are jointly reinforcing ways of sustaining "our society's support for a culture of independence and ... its defense against a culture of conformity"; see Dworkin, "We Need a New Interpretation," 189. And if these twin freedoms are meant to serve the same ideal of ethical individualism, then it might be beneficial to have institutions that evince a commitment to both freedoms, side by side - in which the scholar's exemplary ethical individualism (protected by academic freedom) is emulated by students and campus visitors (communicating under the auspices of free speech). 
rejoinder dovetails with a broader misgiving that one might have about the axes I have been grinding here. In Section I, I said that I am not asking whether we have good reason to accept free speech as a basic civil liberty, or whether we have good reason to accept academic freedom as a governing precept in universities. I said that I am asking why-granting such reasons - we shouldn't move toward a more "partitioned" view, on which academic freedom is the governing norm for communication in universities, and free speech is left to do its work in the wider sphere of public discourse. The misgiving one might have, in essence, is that this question just seems unmotivated, or perhaps perversely motivated.

But there is a real and earnest motivation here. In treating the university campus as the standard view recommends - as a forum for the coexistence of the intellectual seriousness of academic study and the rowdy altercation of wide-open, democratic discourse - we hope that democratic discourse will be elevated and that academic study won't be dragged down. But that may be overly optimistic. The influence might very easily go the opposite way. Now, anxieties about the dumbing down of the university's intellectual culture do not license a retreat into insular, ivory tower elitism. That would be another (arguably worse) way of forsaking our epistemic mission. The appropriate response to this anxiety is to work at improving the quality of discussion that occurs on campus but outside of formal academic settings. Even as disciplinary research is becoming increasingly hyperspecialized, there are more academics than ever, across all corners of the university, who are working at the art of engaging nonspecialist audiences with their research. The popularity of many academic podcasts suggests that there is a significant lay audience with an appetite for such material. And yet simultaneously, the number of platforms at universities being given over to pseudoeducative pageantry and vain, sophomoric tub-thumping would seem to be on the rise-or, at least, not in decline. In such a climate, the university leader or administrator who consults the professoriate and treats their expertise and intellectual standards as a weighty thumb on the scales, in deciding who receives access to the university's communicative platforms, is to be watchfully applauded.

\section{CONGLUSION}

I have indicated some shortcomings in the main arguments for the standard view of the relation between academic freedom and free speech. Proponents of the standard view believe that, in addition to the protections afforded to teaching and research, under principles of academic freedom, other public speech in universities - including commencement addresses, public lectures, other student society events, campus activism, and writing in student newspapers - should be protected by general-purpose free 
speech principles. They think that free speech is constitutive of the university and that "any institution that sets those principles aside can no longer be meaningfully regarded as a proper institution of higher education." ${ }^{8}$ But the epistemic and democratic arguments for that view are unconvincing. Of course, this does not entail that the standard view is completely indefensible. But it awaits a stronger defense.

Until that arrives, there is a natural position to revert to, which is to say that speech expressing ill-informed or badly reasoned ideas need not receive any special protection in universities, except if it falls under the protection of academic freedom, for example, if it occurs as part of the university's formal teaching and research activities. Free speech is a fundamental liberty in social intercourse per se, but it is not a mandatory commitment for the university. Thus, we can at least sometimes exclude or marginalize speakers and ideas that fall short of the intellectual standards which define academia and conduce to its core epistemic aims.

Does this mean that universities can be run as ideologically repressive dictatorships? No. The university should cultivate debate and openmindedness and welcome unorthodox viewpoints. But, to recap one of my points from Section III, our antidogmatic ideals can be-and in universities, I have argued, they should be-put into practice in a way that is more intellectually discriminating than in public discourse per se. Much like individual academic disciplines, the university at large is not obliged to sponsor communicative platforms or venues for expression that manifestly fail to attain to its basic intellectual standards (e.g., coherence, evidential backing, disciplinary understanding). Decisions about who meets this standard should be made in a consistent and relatively transparent way. But in principle, given that proviso, the imposition of such intellectual standards is no more ideologically intolerant than a literary publisher relegating weak manuscripts to the slush pile, or an art gallery choosing not to exhibit work that is hackneyed or derivative. Universities have a defining epistemic mission, and in the way that they host and manage communicative activity they needn't pretend otherwise.

But what does this mean in practice? What actual policies should a university adopt, if it rejects the standard view of the relation between academic freedom and free speech and opts for the alternative approach that I am recommending, on which academic standards of discourse govern all communication that happens under the university's insignia?

In the wake of the Ben Stein controversy, UVM's president pledged to institute a new vetting procedure for the invitation of commencement speakers, which involved consulting with faculty about all invitees. At a programmatic level, this is one kind of practical policy approach that universities should undertake in light of the theoretical stance that I am 
defending. Universities should always look to involve academic experts in decisions about which speakers receive speaking platforms on campus. Now, when members of faculty themselves invite speakers to contribute to faculty-run teaching and research, any managerial oversight must remain "light touch." The idea that faculty should be autonomous in deciding how on-campus teaching and research events are run, including who is invited to speak, follows straightforwardly from a commitment to academic freedom. But for other kinds of speaking invitations - things like commencement addresses, or student society meetings, which are not directly linked to teaching and research-universities should (and note: some already do) have some kind of academic oversight procedures in place. These procedures should, subject to sensible provisos, make it possible for faculty to oppose or block invited speakers on academic grounds. Some institutions require that invited speakers be vetted by a senior administrator. Some institutions require that invited speakers be vetted by student representatives. ${ }^{49}$ The evident defect in these forms of vetting, however, is that they sideline academic expertise. If we want academic standards of discourse to govern all communication that happens under the university's umbrella, then the natural way to achieve that is to give faculty the opportunity to register concerns about the academic credentials of invitees. And where the considered judgment of the institution's academic experts is that an invited speaker's work manifestly fails to attain to the kind of intellectual standards that further its epistemic mission, then, other things being equal, that institution should refrain from offering a platform to that speaker.

I said that this power should be subject to sensible provisos. For one thing, it would be unwise to give individual faculty members a veto power over invitations. Individuals often have idiosyncratic or sectarian views about what counts as academically competent work. Indeed, some faculty have doubts about the competence of their peers in adjacent academic disciplines. The faculty representatives who are tasked with reviewing invited speakers ought to be a representative cross section of an

49. For example, the University of Essex, in its "External Speaker Code of Practice," mandates that invitations to external speakers be reviewed by the university's safeguarding compliance manager, who has the power to approve, refuse, or impose a range of procedural conditions and constraints on the relevant event (see www.essex.ac.uk/student /event/external-speaker). My home institution, University College London, requires that all student union-affiliated clubs and societies seek prior approval for visiting speakers from the Students' Union, which, again, can either deny or impose various procedural conditions and constraints on the relevant event. Given that student clubs and societies must be union affiliated at University College London in order to gain access to most universitybased facilities and funding, this requirement functions as a de facto, student-led vetting procedure on external speakers for clubs and societies; see studentsunionucl.org/how-to -guides/organise-event-with-external-speaker. 
institution's various academic disciplines, and they should reflect the intellectual diversity contained therein. And the collective opinion of these representatives should probably be gauged via some kind of majoritarian process. The cases where we want to avoid platforming speakers are those in which many or most members of a representative group of faculty delegates would judge that the speaker falls short of the institution's intellectual standards. There is room for variation in the fine-grained details of practical implementation, but this is acceptable as long as the processes remain transparent.

With regard to the various kinds of on-campus speech that primarily come from students-like writing in student newspapers, or student activism - there are, again, existing regulatory frameworks through which academic oversight can be implemented. Most universities impose regulations upon student newspapers and student activism. These procedures can either directly or indirectly constrain students' expressive activities on and around campus. Academic staff should have some advisory input in these regulations, then. They shouldn't be entirely overseen by administrators. Again, if a university wants academic standards of discourse to govern all communication that occurs under its umbrella, then it should seek sensible ways to elicit input from its own academics when it comes to these sorts of regulations.

Beyond these kinds of programmatic recommendations, trying to specify a universal policy template for universities to follow is unlikely to be helpful. Different institutional cultures and management setups call for different kinds of regulatory practices. And there are a variety of reasonable policy approaches that universities can adopt in relation to these issues. The overall point of critiquing the standard view-and of arguing for an alternative, on which academic standards apply beyond overt teaching and research contexts - is not to try to establish some kind of one-size-fits-all policy recommendation. The key point is to clarify which ideals universities should be answering to when working through these policy issues. ${ }^{50}$

50. There are other difficult policy issues to contend with beyond no platforming and "disinvitation incidents." Universities will become very dreary if they refuse to host entertainment events. But academic vetting processes will become utterly toothless if events involving the Ben Steins and Milo Yiannopouloses of the world can simply be rebadged as entertainment and thereby exempted from any academic oversight. So how do we distinguish, in a principled way, between events to which academic standards are applicable and events that are merely recreational? Here is another problem. On any plausible view of how universities should be run, students, staff, and visitors shouldn't be taken to forfeit their ordinary civil rights of speech, movement, and association simply by virtue of setting foot on a campus. While the university may have good reasons to refrain from supporting some student publications or activist groups, this does not entitle it to infringe on any student's ordinary civil liberties. But then how do we distinguish between communicative activities that occur under the university's aegis and those that are merely occurring on the university's 
If we hold the standard view — and center free speech among those ideals - then we will be troubled by cases like the Stein episode at UVM, in which an invited commencement speaker lost a platform because of his purportedly dismal intellectual track record. At the same time, if we hold the standard view, we won't be too troubled by cases in which shills, trolls, and paranoid conspiracy theorists are given desirable speaking opportunities at student society events. While we may not think that these speakers represent our university's intellectual ideals, the very essence of free speech is that such voices are to be answered with more speech, instead of simply being muzzled. By contrast, if we reject the standard view, our perspective on these cases - and on the array of policy options one might adopt, in relation to similar cases - looks rather different. Most importantly, instead of the anything-goes permissiveness that is characteristic of a free speech ethos, we will be more disposed to vet ideas and speakers in advance, and to do that in a way that calls upon the intellectual expertise and judgment of the institution's own academic experts. If a clear majority of faculty representatives believe that inviting some particularly disreputable speaker to campus will undermine the intellectual mission that they are working to achieve, in their teaching and research, this will generally be a good reason to withhold or withdraw an invitation. Friends of the standard view have reason to regard this kind of approach with a suspicious eye. Those who reject the standard view will tend to regard it as evidence of an institution that takes its epistemic mission seriously.

premises? When can the university say, "These are our premises, and we aren't here to host this sort of thing," and when would that shade into despotism? These are policy challenges for any university, including those that purport to be bastions of free speech. In any case, again, the point of criticizing the standard view is not to resolve all such issues but to clarify which ideals universities should be aspiring to in working through such issues. 